\title{
A Potential Role for Nerve Growth Factor in Regulating the Maturation of Inhibitory Neurotransmission
}

\author{
Daniel L. Jones \\ Department of Neurobiology, Duke University Medical Center, Durham, North Carolina 27710 \\ Review of Lagostena et al.
}

Interneurons mediate inhibition in the CNS by releasing GABA, which hyperpolarizes postsynaptic neurons by promoting chloride entry through $\mathrm{GABA}_{\mathrm{A}}$ receptors. Low levels of intracellular chloride $\left(\left[\mathrm{Cl}^{-}\right]_{\mathrm{i}}\right)$ in postsynaptic neurons, maintained by the chloride exporter $\mathrm{KCC} 2$, are required for the hyperpolarizing activity of GABA (Rivera et al., 1999).

During early postnatal development, KCC2 expression is low, while expression of the chloride importer NKCC1 is elevated. As a result, $\left[\mathrm{Cl}^{-}\right]_{\mathrm{i}}$ is increased, making the reversal potential of GABA-mediated currents $\left(E_{\mathrm{GABA}}\right)$ depolarized relative to the resting membrane potential in young neurons. Consequently, GABA activates chloride efflux through $\mathrm{GABA}_{\mathrm{A}}$ receptors and depolarizes postsynaptic neurons (Plotkin et al., 1997; Rivera et al., 1999).

While the relative contributions of NKCC1 and KCC2 to chloride homeostasis are well understood, the molecular mechanisms responsible for regulating their expression during development remain unclear. Evidence from the chick ciliary ganglion has implicated nicotinic cholinergic signaling in the regulation of developmental changes in KCC2 and NKCC1 expression. Calcium influx through nicotinic acetylcho-

Received March 12, 2010; revised April 8, 2010; accepted April 9, 2010.

I am supported by the Duke Postdoctoral Training Program in Fundamental and Translational Neuroscience. I thank Dr. James McNamara for helpful comments on this manuscript.

Correspondence should be addressed to Daniel L. Jones, 413 Bryan Research Building, Department of Neurobiology, Research Drive, Duke University Medical Center, Durham, NC27710. E-mail:jones@neuro.duke.edu. DOI:10.1523/JNEUROSCI.1283-10.2010

Copyright $\odot 2010$ the authors $\quad$ 0270-6474/10/306813-02\$15.00/0 line receptors (nAChRs) activates the transcription factor CREB, which is thought to result in upregulation of KCC2 and downregulation of NKCC1 as early postnatal development progresses (Liu et al., 2006).

Recent work from Lagostena et al. (2010), using mice with deficient nerve growth factor (NGF) signaling, highlights NGF as another potentially important factor in regulation of chloride homeostasis. In this study, the consequences of NGF loss were examined using AD11 mice, which express antibodies directed against NGF. These mice exhibit impaired NGF signaling, neurodegeneration, and cognitive dysfunction (Capsoni et al., 2000). Lagostena et al. (2010) examined 6-month-old AD11 mice, an age at which NGF deprivation had begun to induce neurodegeneration and other defects.

In AD11 mice, Lagostena et al. (2010) found that GABA depolarized, rather than hyperpolarized, adult hippocampal neurons. Consistent with the prediction that hippocampal neurons in these mice exhibit high $\left[\mathrm{Cl}^{-}\right]_{\mathrm{i}}$, the authors report that KCC2 mRNA and protein were both reduced in the AD11 mouse hippocampus. The authors propose that loss of NGF signaling turns on the same genetic program that is active during early development, resulting in downregulation of KCC2 and chloride accumulation. These results suggest that NGF may play a role in maintaining the hyperpolarizing nature of GABAergic transmission.

Lagostena et al. (2010) first presented electrophysiological data from hippocampal slices demonstrating that GABA depo- larizes CA1 pyramidal neurons in $\mathrm{AD} 11$ mice. In cell-attached recordings, the $\mathrm{GABA}_{\mathrm{A}}$ receptor agonist isoguvacine reduced firing in wild-type neurons but increased firing in AD11 neurons. In agreement with this finding, extracellular recordings of multiunit activity showed that isoguvacine inhibited population activity in slices from wild-type animals but increased activity in slices from AD11 animals.

To examine potential network effects of excitatory GABA in AD11 mice, the authors recorded glutamate-mediated spontaneous EPSCs (sEPSCs) in pyramidal neurons from wild-type and AD11 mice. Because these recordings were obtained in the whole-cell configuration with identical intracellular recording solutions, $\left[\mathrm{Cl}^{-}\right]_{\mathrm{i}}$ was clamped to the same level in both wild-type and AD11 cells. This methodology allowed for the putative isolation of glutamatergic sEPSCs by holding cells at $-70 \mathrm{mV}$, which the authors reported to be the reversal potential for GABA-mediated currents under these conditions. In these experiments, application of the $\mathrm{GABA}_{\mathrm{A}}$ receptor antagonist bicuculline reduced sEPSC frequency in AD11 pyramidal neurons without affecting sEPSC frequency in wild-type cells.

Lagostena et al. (2010) interpret these results as further evidence that GABA acts to excite pyramidal neurons in AD11 mice. The authors argue that, in the presence of bicuculline, GABA-mediated excitatory drive of $\mathrm{AD} 11$ pyramidal neurons is eliminated, leading to reduced glutamatergic output from these cells. However, the authors do not report having administered glutamate receptor antagonists to confirm that, in the 
absence of bicuculline, all events recorded at $-70 \mathrm{mV}$ were glutamatergic. As such, it is possible that some synaptic currents recorded at $-70 \mathrm{mV}$ may be GABAergic and thus bicuculline sensitive, complicating the interpretation of these results. A control experiment showing that application of glutamate receptor antagonists eliminates all events recorded at $-70 \mathrm{mV}$ in both wildtype and $\mathrm{AD} 11$ mice would be necessary to rule out this possibility.

Next, the authors demonstrated depolarizing activity of GABA in AD11 mice by obtaining perforated patch recordings from wild-type and AD11 neurons. These recordings allow estimation of $E_{\mathrm{GABA}}$ by leaving intracellular chloride levels undisturbed. As predicted by whole-cell and extracellular recordings, $E_{\mathrm{GABA}}$ was significantly depolarized compared to resting membrane potential in AD11 mice, whereas in wild-type mice, $E_{\mathrm{GABA}}$ was hyperpolarized relative to resting membrane potential. These results were confirmed in cell-attached singlechannel recordings of $\mathrm{GABA}_{\mathrm{A}}$ receptors.

Finally, Lagostena et al. (2010) analyzed levels of KCC2 mRNA and protein in AD11 mice using real-time qRT-PCR and immunohistochemistry. Consistent with their electrophysiological data suggesting elevated $\left[\mathrm{Cl}^{-}\right]_{\mathrm{i}}$ in $\mathrm{AD} 11$ mice, the authors found that hippocampal KCC2 mRNA and protein were reduced in these animals compared to wild-type mice. In additional qRT-PCR experiments, the authors found reduced basal forebrain mRNA levels of some nAChR subunits, consistent with their previous report that cholinergic signaling is disrupted in AD11 mice (Rosato-Siri et al., 2006).

Together, these results show that chronic expression of anti-NGF antibodies is associated with downregulation of KCC2 in adult hippocampal neurons, resulting in enhanced $\left[\mathrm{Cl}^{-}\right]_{\mathrm{i}}$ and a depolarizing shift in $E_{\mathrm{GABA}}$. The authors argue that these results implicate NGF in the maturation of GABAergic inhibition in early postnatal development, and propose that NGF deprivation leads to depolarization of $E_{\mathrm{GABA}}$ by disrupting the function of the cholinergic system within the basal forebrain. Indeed, it is unlikely that loss of NGF signaling has direct effects within the hippocampus, because the NGF receptor TrkA is largely absent from this region in adults (Sobreviela et al., 1994).

While this model is attractive, the observation that $E_{\mathrm{GABA}}$ is similarly depolarized in AD11 mice and early postnatal mice is not evidence of a shared genetic program underlying these phenomena. Impairment of NGF signaling results in a long list of phe- notypes in $\mathrm{AD} 11$ mice, ranging from $\mathrm{cy}-$ toskeletal defects to neurodegeneration and memory deficits (Capsoni et al., 2000). While some of these effects are presumably direct results of impaired NGF signaling, other phenotypes of AD11 mice are likely to be secondary effects due to neurodegeneration or other alterations. Whether downregulation of KCC2 and depolarization of $E_{\mathrm{GABA}}$ are direct results of NGF blockade remains unknown. In addition, anti-NGF antibodies may exhibit off-target effects, directly inhibiting other pathways that were not examined in the initial characterizations of AD11 mice.

Although cholinergic function has been implicated in regulating the developmental $\left[\mathrm{Cl}^{-}\right]_{\mathrm{i}}$ shift in the chick ciliary ganglion (Liu et al., 2006), it is not clear whether reduced expression of $\mathrm{nAChR}$ subunits in $\mathrm{AD} 11$ mice directly results from loss of NGF signaling. Furthermore, there is no evidence of a causal link between reduced cholinergic function in AD11 mice and the observed depolarization of $E_{\mathrm{GABA}}$. It is likely that expression levels of many genes are altered in these animals. Consequently, it is difficult to determine whether these changes are a direct result of NGF blockade rather than the result of phenomena like widespread neurodegeneration.

Signaling through TrkB receptors by brain-derived neurotrophic factor (BDNF) has also been implicated in regulation of chloride homeostasis. In response to elevated neural activity in hippocampal slices, BDNF expression is increased. BDNF in turn activates $\mathrm{TrkB}$ receptors, which leads to downregulation of KCC2 (Rivera et al., 2004). Interestingly, BDNF is known to be downregulated in Alzheimer's disease patients and in mouse models of Alzheimer's disease (Peng et al., 2009), although BDNF levels have not been examined in AD11 mice. In the presence of excessive excitation due to depolarizing GABA responses, however, one might expect BDNF to instead be upregulated in $\mathrm{AD} 11$ mice. This raises the possibility that increased BDNF levels in these animals may lead to downregulation of KCC2 via TrkB signaling.

The findings reported by Lagostena et al. (2010) raise a number of questions regarding the function of inhibitory circuits in AD11 mice. For instance, the developmental progression of $E_{\mathrm{GABA}}$ may be disrupted in these animals such that GABA remains depolarizing throughout development and adulthood. Alternatively, maturation of GABAergic transmission from depolarizing to hyperpolarizing may proceed normally in NGF-deprived animals, only to be reversed at later ages. Normal ini- tial development of GABA signaling is a possibility in $\mathrm{AD} 11$ mice, because anti-NGF antibodies and inhibition of NGF signaling are not detectable in these animals until P45, an age by which GABA has already acquired its hyperpolarizing activity in normal mice (Ben-Ari, 2002).

In sum, Lagostena et al. (2010) have presented an intriguing set of experiments highlighting a potential role for NGF signaling in regulation of chloride homeostasis. Further studies are required to determine whether NGF signaling directly regulates KCC2 expression and $E_{\mathrm{GABA}}$ in $\mathrm{AD} 11$ mice as well as in the early postnatal brain.

\section{References}

Ben-AriY (2002) Excitatory actions of gaba during development: the nature of the nurture. Nat Rev Neurosci 3:728-739.

Capsoni S, Ugolini G, Comparini A, Ruberti F, Berardi N, Cattaneo A (2000) Alzheimer-like neurodegeneration in aged antinerve growth factor transgenic mice. Proc Natl Acad Sci U S A 97:6826-6831.

Lagostena L, Rosato-Siri M, D’Onofrio M, Brandi R, Arisi I, Capsoni S, Franzot J, Cattaneo A, Cherubini E (2010) In the adult hippocampus, chronic nerve growth factor deprivation shifts GABAergic signaling from the hyperpolarizing to the depolarizing direction. J Neurosci 30:885-893.

Liu Z, Neff RA, Berg DK (2006) Sequential interplay of nicotinic and GABAergic signaling guides neuronal development. Science 314:1610-1613.

Peng S, Garzon DJ, Marchese M, Klein W, Ginsberg SD, Francis BM, Mount HT, Mufson EJ, Salehi A, Fahnestock M (2009) Decreased brainderived neurotrophic factor depends on amyloid aggregation state in transgenic mouse models of Alzheimer's disease. J Neurosci 29:9321-9329.

Plotkin MD, Snyder EY, Hebert SC, Delpire E (1997) Expression of the Na-K-2Cl cotransporter is developmentally regulated in postnatal rat brains: a possible mechanism underlying GABA's excitatory role in immature brain. J Neurobiol 33:781-795.

Rivera C, Voipio J, Payne JA, Ruusuvuori E, Lahtinen H, Lamsa K, Pirvola U, Saarma M, Kaila K (1999) The $\mathrm{K}^{+} / \mathrm{Cl}^{-}$co-transporter KCC2 renders GABA hyperpolarizing during neuronal maturation. Nature 397:251-255.

Rivera C, Voipio J, Thomas-Crusells J, Li H, Emri Z, Sipilä S, Payne JA, Minichiello L, Saarma M, Kaila K (2004) Mechanism of activity-dependent downregulation of the neuron-specific K-Cl cotransporter KCC2. J Neurosci 24:46834691.

Rosato-Siri M, Cattaneo A, Cherubini E (2006) Nicotine-induced enhancement of synaptic plasticity at CA3-CA1 synapses requires GABAergic interneurons in adult anti-NGF mice. J Physiol 576:361-377.

Sobreviela T, Clary DO, Reichardt LF, Brandabur MM, Kordower JH, Mufson EJ (1994) TrkAimmunoreactive profiles in the central nervous system: colocalization with neurons containing p75 nerve growth factor receptor, choline acetyltransferase, and serotonin. J Comp Neurol 350: 587-611. 